\title{
Laparoscopic Madigan Prostatectomy
}

\author{
Changyi Quan, M.D., Ph.D.,, ${ }^{1,2}$ Wenliang Chang, M.D., Jing Chen, M.D., ${ }^{2}$ \\ Bo Li, M.D., ${ }^{2}$ and Yuanjie Niu, M.D., Ph.D., ${ }^{1,2}$
}

\begin{abstract}
Purpose: Laparoscopic Madigan prostatectomy have not been reported yet. We modified the Madigan prostatectomy to make it suitable for laparoscopically enucleating hyperplastic glands larger than $100 \mathrm{~g}$.

Patients and Methods: Between May 2007 and Oct 2008, extraperitoneal laparoscopic prostatectomy with maintenance of the intact urethra had been performed on 16 patients with benign prostatic hyperplasia (BPH) and glands larger than $100 \mathrm{mg}$. To make it suitable for laparoscopic use, two major modifications had been made: (1) Open the prostate capsule near the bladder neck without sutures along the opening; (2) identify the bladder neck mucosa before recognizing the urethra. All patients were evaluated preoperatively and postoperatively. Data were compared with those from open surgeries.

Results: All laparoscopic procedures were successful with the total operative time of $111.8 \pm 28.6$ minutes, which had no significant difference compared with open surgeries. Estimated blood loss of laparoscopic procedures $(112.5 \pm 47.8 \mathrm{~mL})$ was significantly lower than that of open surgery. The catheterization time and hospital stay time was significantly shorter than open surgery. The improvement of the International Prostate Symptom Score, maximum flow rate, and quality-of-life score were not different between the comparing groups.

Conclusions: The laparoscopic Madigan prostatectomy is a safe and feasible approach for large glands (BPH). Furthermore, its advantages include shorter learning curve, reduced blood loss, less retroejaculation rate, shorter catheterization time, and shorter hospital stay.
\end{abstract}

\section{Introduction}

T He open Madigan pRostatectomy, first described in $1990,{ }^{1}$ has been known in the last two decades for a perfect concept of preserving the intact urethra while removing the hyperplastic glands. Although the rationale for removing lesions and saving the nearby functional normal structures as much as possible fits well the modern concept of minimally invasive surgery, however, the advantages of this surgery have seldom been appreciated because of the difficult identification of the urethra and low success rate with the poor view of naked eyes.

We present our modification of the Madigan prostatectomy to make it suitable for laparoscopic enucleation of the hyperplastic gland larger than $100 \mathrm{~g}$.

Today, benign prostatic hyperplasia $(\mathrm{BPH})$ is commonly managed with transurethral resection of the prostate (TURP). For lesions larger than $100 \mathrm{~g}$, however, it remains a big challenge for most TURP surgeons. In China, some urologists would rather choose traditional open surgical procedures ${ }^{2-5}$ than TURP, because the open procedures offer good longterm functional results compared with those of TURP. ${ }^{6-8}$

The open simple prostatectomy has been successfully transferred to the laparoscopic approaches with Millin tech- niques as described by Rehman and associates. ${ }^{9}$ Recent reports indicate that it offers advantages exceeding its open predecessor; in addition, both operations are comparable in improving prostate symptoms and quality of life. ${ }^{10-12}$ Indeed, a laparoscopic approach has brought proven benefits, including lower morbidity, limited pain, shorter hospital stay, and earlier return to normal working activities. Thus, the laparoscopic Millin prostatectomy has the potential to combine the advantages of a minimally invasive technique with the favorable results of open surgery. Our efforts with the laparoscopic Madigan prostatectomy have not been reported, however.

\section{Patients and Methods}

From May 2007 to Oct 2008, extraperitoneal laparoscopic prostatectomy with urethra preservation was performed on 16 patients. All the patients had symptomatic $\mathrm{BPH}$, and the volumes of their prostates were larger than $100 \mathrm{cc}$ measured by transrectal ultrasonography. All 16 patients were evaluated with the International Prostate Symptom Score (IPSS) and quality-of-life (QoL) questionnaires, maximum flow rate (Qmax) and urodynamic studies, serum prostate-specific antigen (PSA) test, and digital rectal examination preoperatively.

\footnotetext{
${ }^{1}$ Department of Urology, Tianjin Institute of Urology, Tianjin, China.

${ }^{2}$ Department of Urology, the 2nd Hospital of Tianjin Medical University, Tianjin, China.
} 
IPSS questionnaires and Qmax were also evaluated 2 months after surgery.

Two sample $t$ test was used for the statistical analysis, and $P<0.05$ was considered as the criterion of statistical significance.

\section{Surgical technique}

After the general anesthesia had been induced, the patient was prepped and draped in a supine, slight Trendelenburg position with a rolled towel under the lumbar curvature and the table slightly broken at about 15 degrees to extend the lower abdomen. A 20F Foley urethral catheter was placed with balloon inflated.

A $20-\mathrm{mm}$ semicircle incision was made in the infraumbilical crease, and the anterior rectus fascia was incised vertically. The rectus muscle fibers were separated vertically, exposing the posterior rectus fascia. The space between the rectus muscle and the posterior rectus sheath was bluntly developed by finger dissection; then, a self-made balloon was inserted through the space toward the pubis. The balloon was slowly inflated with $500 \mathrm{~mL}$ air to develop the retropubic working space. After placement of a $10-\mathrm{mm}$ trocar into the umbilical incision, the 0 -degree laparoscope was put in and a $10-\mathrm{mm}$ trocar was placed in each side lateral to the rectus muscle on the umbilicus plane under observation. High-flow carbon dioxide insufflation was used up to 10 to $15 \mathrm{~mm} \mathrm{Hg}$. A $5-\mathrm{mm}$ trocar was placed in the iliac fossa at the level of a socalled McBurney point on either side under visual control. The areolar tissue and fat were coagulated and swept gently from the anterior surface of the bladder and prostate using bipolar forceps.

The superficial veins over the prostate were carefully coagulated. The junction of the bladder and the prostate is clearly identified by moving the catheter. The most important of our improvements is to make a transversal incision near the prostatic-vesical junction (Fig. 1) as long as crossing the base of the prostate. The capsular incision is deepened by mono-

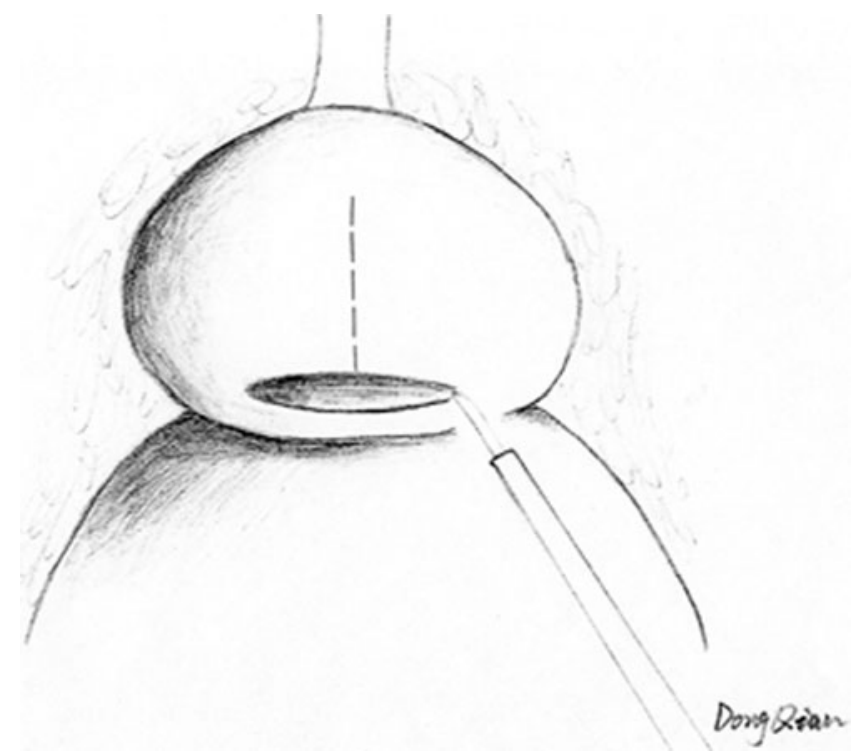

FIG. 1. Transversal incision near the prostatovesical junction crossing the base of the prostate. polar (or bipolar) coagulation until the exposure of the plane between the prostatic surgical capsule and the adenomatous tissue. The incision near the bladder neck allowed good blood control and a possibility of managing the enlarged middle lobe. Capsular sutures along both sides of the incision as described previously ${ }^{9}$ were not necessary.

After incision, the surgical capsular plane was developed distally, and the isthmus was cut open toward the apex by harmonic scalpel, so that the prostate is divided into two separate lobes (Fig. 2). The urethra can easily be identified near the border of the prostate and bladder neck between the right and left lobes. The urethra was carefully divided from the prostate by sharp dissection, and the urethra was fully preserved (Fig. 3). Then the surgical capsular plane was sequentially developed laterally to the posterior plane and cranially to the bladder neck. Finally, the right and left lobes were divided by posterior excision of the prostate until the whole hyperplastic nodules were freed. After the specimens were taken out of their positions, the capsular incision was closed by running suture (2/0 polyglactin on a tapered needle) (Fig. 4). An EndoBag was introduced. and the specimens were taken out through the umbilical port. A drain was placed via the right 5 -mm port.

\section{Results}

All 16 cases of extraperitoneal laparoscopic prostatectomy were successful without open conversions. Among them, roughly $20 \%$ had urethral lacerations. The total operative time was $111.8 \pm 28.6$ minutes, compared with other open surgery data $^{12}$; there was no significant difference in operative time. Estimated blood loss was $112.5 \pm 47.8 \mathrm{~mL}$; it was significantly lower than that of open surgery, and no patient needed transfusions. Drain removal was performed in 24 to 48 hours. The Foley catheter was removed when the urine was totally clear, usually in 2 days after operation. The analgesic requirement was minimal, and hospital stay was $3.5 \pm 0.8$ days after operation. The catheterization time and hospital stay

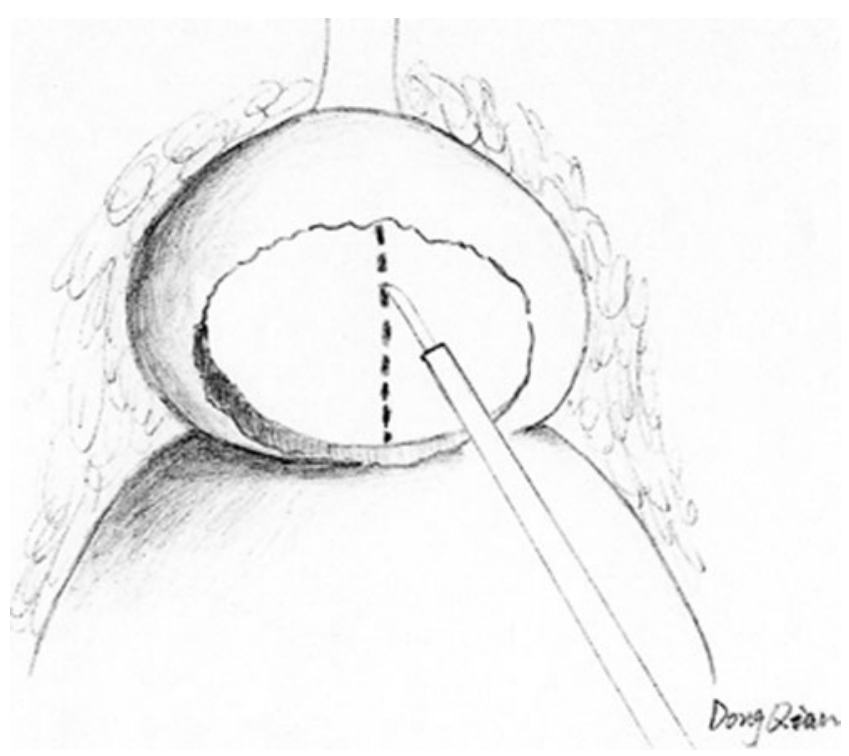

FIG. 2. The isthmus was cut open toward the apex by harmonic scalpel. 


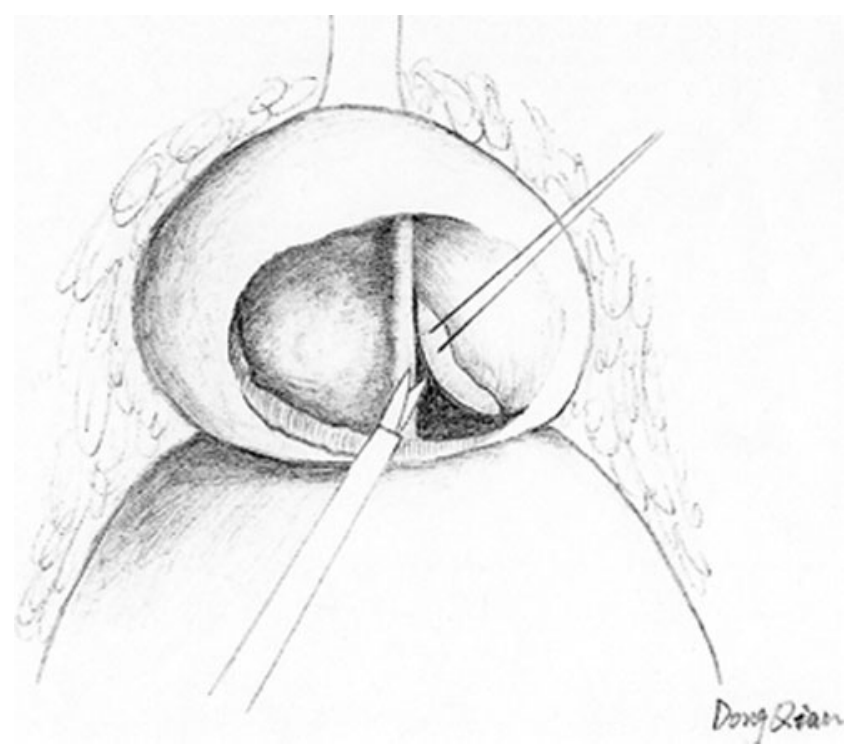

FIG. 3. The urethra was carefully divided from the prostate by sharp dissection.

time were significantly shorter than those of open surgery, and there were statistical differentiations (Table 1).

The enucleated prostate specimen weight was $104.7 \pm 23.3 \mathrm{~g}$; it was equal to $79.1 \%$ of the prostate volume estimated on preoperative transrectal ultrasonography. These data are the same as described by Porpiglia and colleagues. ${ }^{12}$ Follow-up examination at 2 months showed that the Qmax was $22.3 \pm 1.6 \mathrm{~mL} / \mathrm{s}$; the IPSS score was $4.5 \pm 1.8$, and QoL score was $0.5 \pm 0.5$. Compared with preoperative data, there were visible improvements on IPSS, Qmax, and QoL scores (Table 2). The erectile function was preserved in all the patients who were potent before surgery. No urinary incontinence was reported by patients.

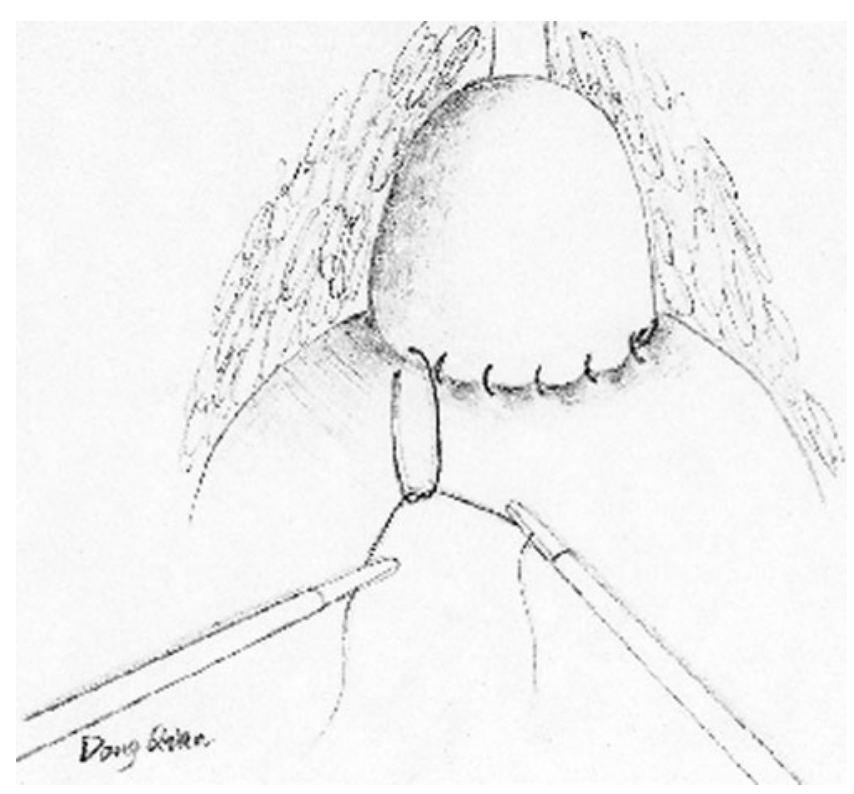

FIG. 4. Closure of the capsular incision with polyglactin sutures.
TABle 1. Comparison of Transcapsular Laparoscopic Surgery and Open Surgery (Millin)

\begin{tabular}{lccc}
\hline & $\begin{array}{c}\text { Laparoscopic } \\
\text { surgery }\end{array}$ & $\begin{array}{c}\text { Open } \\
\text { surgery }\end{array}$ & $\begin{array}{c}\mathrm{P} \\
\text { value }\end{array}$ \\
\hline Number of patients & 16 & 20 & \\
Mean age (y) & $65.2 \pm 5.8$ & $67.8 \pm 6.8$ & $>0.05$ \\
Operative time (min) & $111.8 \pm 28.6$ & $95.5 \pm 22.5$ & $>0.05$ \\
Blood loss (mL) & $112.5 \pm 47.8$ & $687.5 \pm 298.6$ & $\varangle 0.001$ \\
Catheterization time (d) & $3.1 \pm 0.4$ & $5.6 \pm 1.1$ & $\varangle 0.001$ \\
Hospital stay (d) & $3.5 \pm 0.8$ & \pm & $\varangle 0.001$ \\
Prostate volume (cc) & $132.3 \pm 21.9$ & $115.6 \pm 40.0$ & $>0.05$ \\
$\quad$ TRUS) & & & \\
Removed adenoma (cc) & $104.7 \pm 23.3$ & $88.1 \pm 43.8$ & $>0.05$ \\
\hline
\end{tabular}

TRUS $=$ transrectal ultrasonography.

The overall follow-up was $19.6 \pm 4.2$ months. In this period, there were no complications found, such as urinary inflammation and urethral stenosis.

\section{Discussion}

TURP represents the optional surgical treatment option for the medium-size prostate, for the prostate larger than $70 \mathrm{~g}$. Although resection ratios increased, with the largest occurring in prostates of 71 to $100 \mathrm{~g}$, the surgeon resects no more than $50 \%$ of the gland volume. ${ }^{13}$ Prostates larger than $100 \mathrm{~g}$ have been managed traditionally with open surgical procedures. $^{2-5}$ Open prostatectomy accounts for $14 \%$ to $32 \%$ of the total invasive procedures for $\mathrm{BPH}$ in Europe; in other countries, this rate is as high as $68 \%{ }^{6,14-16}$

In recent days, a majority of urologic surgeries are performed laparoscopically. Mariano and coworkers ${ }^{17}$ first reported a transperitoneal approach for retropubic simple prostatectomy. ${ }^{10}$ More recently, extraperitoneal laparoscopic transcapular prostatectomy (Millin) has been proposed; minimal bleeding, a reduced transfusion rate, shorter hospitalization, and faster recovery were its additional advantages. This minimally invasive technique is a reasonable alternative to the open simple prostatectomy for large glands with reduced morbidity. ${ }^{11,12,18}$

In our laparoscopic Madigan prostatectomy procedure, we had made several modifications on the previous operation. The first improvement is bleeding control. To our knowledge, the figure-of eight stay sutures at the prostate and bladder on either side of the prostatovesical junction is not necessary. The bleeding can be controlled easily by bipolar or monopolar

Table 2. Comparison of Preoperative ANd Postoperative Data

\begin{tabular}{lccc}
\hline & Preoperative & Postoperative & P value \\
\hline IPSS & $28.6 \pm 3.8$ & $4.5 \pm 1.8$ & $<0.001$ \\
Qmax $(\mathrm{mL} / \mathrm{s})$ & $6.4 \pm 1.5$ & $22.3 \pm 1.6$ & $<0.001$ \\
QoL & $5.3 \pm 0.5$ & $0.5 \pm 0.5$ & $<0.001$ \\
$\begin{array}{l}\text { Urinary incontinence } \\
\quad(\text { case) }\end{array}$ & 0 & 0 & - \\
$\begin{array}{l}\text { Sexual dysfunction } \\
\quad \text { (case) }\end{array}$ & 0 & 0 & - \\
\hline
\end{tabular}

IPSS = International Prostate Symptom Score; Qmax=maximum flow rate; $\mathrm{QoL}=$ quality of life. 
coagulation. Second is the incision site. We have selected a transversal incision on the prostate capsule that is proximal to the prostatovesical junction; this is useful to handle the bleeding and enlarged middle lobe.

Third is urethra preservation. It is beneficial to the postoperative bleeding reduction, no bladder irrigation, shorter catheterization time, and shorter hospital stay, and there is no retroejaculation. It may also be beneficial to the prevention of stenosis of the membranous urethra; but longer term followup is needed for confirmation.

Compared with open surgery (Millin) reported by Porpiglia and associates, ${ }^{12}$ there has been significant improvement in blood loss, catheterization time, and hospital stay $(P<0.001)$ (Table 1) in laparoscopic surgery in the group with preservation of the urethra. There are no differences in operative time, prostate volume (transrectal ultrasonography [TRUS]), and removed gland volume $(P>0.05)$ (Table 1$)$. They also have compared laparoscopic surgery with open surgery; the results have shown that laparoscopic surgery is comparable to open surgery with the advantage of lower blood loss, but there is no difference in catheterization time and hospital stay, which differs from our result. This difference could be induced by urethra preservation, which is very useful for the reduction of catheterization time and hospital stay.

For the enucleated prostate specimen weight, our result was $104.7 \pm 23.3 \mathrm{gm}$; this was equal to $79.1 \%$ of the prostate volume estimated on preoperative TRUS, which is similar to previous description. ${ }^{12,19}$ During our 19.6 \pm 4.2 months follow-up, compared with preoperative data, there were visible improvements on IPSS, Qmax. and QoL scores. Further observation is still needed for long-term outcome.

\section{Conclusion}

Laparoscopic Madigan prostatectomy with preservation of the urethra is a safe and feasible approach for large BPH. The benefits of laparoscopic Madigan prostatectomy, including a short learning curve, early removal of the catheter, the absence of postoperative lower urinary tract symptoms and hematuria, a shorter period of hospitalization, and lower incidence of retrograde ejaculation and erectile dysfunction, etc, had been characterized.

\section{Disclosure Statement}

No competing financial interests exist.

\section{References}

1. Dixon AR, Lord PH, Madigan MR. The Madigan prostatectomy. J Urol 1990;144:1401-1403.

2. de la Rosette JJ, Alivizatos G, Madersbacher S, et al. EAU guidelines on benign prostatic hyperplasia (BPH). Eur Urol 2001;40:256-264.

3. Roehrborn CG, Bartsch G, Kirby R, et al. Guidelines for the diagnosis and treatment of benign prostatic hyperplasia: $A$ comparative, international overview. Urology 2001;58:642-650.

4. Moody JA, Lingeman JE. Holmium laser enucleation for prostate adenoma greater than $100 \mathrm{gm}$.: Comparison to open prostatectomy. J Urol 2001;165:459-462.

5. Kuntz RM, Lehrich K. Transurethral holmium laser enucleation versus transvesical open enucleation for prostate adenoma greater than 100 gm.: A randomized prospective trial of 120 patients. J Urol 2002;168:1465-1469.
6. Serretta V, Morgia G, Fondacaro L, et al. Open prostatectomy for benign prostatic enlargement in southern Europe in the late 1990s: A contemporary series of 1800 interventions. Urology 2002;60:623-627.

7. Gratzke C, Schlenker B, Seitz M, et al. Complications and early postoperative outcome after open prostatectomy in patients with benign prostatic enlargement: Results of a prospective multicenter study. J Urol 2007;177:1419-1422.

8. Varkarakis I, Kyriakakis Z, Delis A, et al. Long-term results of open transvesical prostatectomy from a contemporary series of patients. Urology 2004;64:306-310.

9. Rehman J, Khan SA, Sukkarieh T, et al. Extraperitoneal laparoscopic prostatectomy (adenomectomy) for obstructing benign prostatic hyperplasia: transvesical and transcapsular (Millin) techniques. J Endourol 2005;19:491-496.

10. Baumert H, Ballaro A, Dugardin F, Kaisary AV. Laparoscopic versus open simple prostatectomy: A comparative study. J Urol 2006;175:1691-1694.

11. Mariano MB, Graziottin TM, Tefilli MV. Laparoscopic prostatectomy with vascular control for benign prostatic hyperplasia. J Urol 2002;167:2528-2529.

12. Porpiglia F, Terrone C, Renard J, et al. Transcapsular adenomectomy (Millin): A comparative study, extraperitoneal laparoscopy versus open surgery. Eur Urol 2006;49:120-126.

13. Green JS, Bose P, Thomas DP, et al. How complete is a transurethral resection of the prostate? Br J Urol 1996; 77:398-400.

14. Tubaro A, Montanari E. Management of symptomatic BPH in Italy: Who is treated and how? Eur Urol 1999;36(suppl 3):28-32.

15. Lukacs B. Management of symptomatic BPH in France: Who is treated and how? Eur Urol 1999;36(suppl 3):14-20.

16. Pilpel D, Porath A, Peleg A. Quantitative evaluation of prostatectomy for benign prostatic hypertrophy under a national health insurance law: A multi-centre study. J Eval Clin Pract 2002;8:9-18.

17. Mariano MB, Tefilli MV, Graziottin TM, et al. Laparoscopic prostatectomy for benign prostatic hyperplasia-a six-year experience. Eur Urol 2006;49:127-132.

18. van Velthoven R, Peltier A, Laguna MP, Piechaud T. Laparoscopic extraperitoneal adenomectomy (Millin): Pilot study on feasibility. Eur Urol 2004;45:103-109.

19. Sotelo R, Spaliviero M, Garcia-Segui A, et al. Laparoscopic retropubic simple prostatectomy. J Urol 2005;173:757-760.

Address correspondence to: Yuanjie Niu, M.D., Ph.D. Department of Urology Tianjin Institute of Urology, Tianjin, China 23 Pingjiang road, Hexi district, Tianjin, 300211

China

E-mail: niuyuanjie@gmail.com

\begin{aligned} & \multicolumn{1}{c|}{ Abbreviations Used } \\ & $\mathrm{BPH}=$ benign prostatic hyperplasia \\ & $\mathrm{IPSS}=$ International Prostate Symptom Score \\ & $\mathrm{Qmax}=$ maximum flow rate \\ & $\mathrm{QOL}=$ quality of life \\ & $\mathrm{PSA}=$ prostate-specific antigen \\ & $\mathrm{TRUS}=$ transrectal ultrasonography \\ & $\mathrm{TURP}=$ transurethral resection of the prostate \end{aligned}

